individuals seen in both 1958 and 1968 the numbers of women with P.C.V.s below $35 \%$ were 3 and 6 respectively; the numbers of men with P.C.V.s below $40 \%$ were 8 and 13 respectively. This increase in the number of subjects with low P.C.V.s in 1968 may be related to seasonal variation. Pucher et al. (1934), in four volunteers, found the highest P.C.V.s in late spring (the time of the 1958 survey) and some of the lowest levels in the autumn (the time of the follow-up in 1968). Clearly there are very considerable difficulties in determining any changes in prevalence in the distributions of haemoglobin or P.C.V.s.

Of 13 women below $12 \mathrm{~g} . / 100 \mathrm{ml}$. in 1958 , three were again below $12 \mathrm{~g} . / 100 \mathrm{ml}$. in 1968 (Table VII). Of $12 \mathrm{men}$ below $12.5 \mathrm{~g} . / 100 \mathrm{ml}$, in 1958 , only one was again below that level in

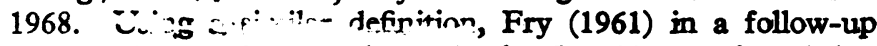
of anaemic cases in general practice for 5 to 10 years found that one-third unre still anaemic. Beveridge et al. (1965) studied 378 hospital inpatients with hypochromic anaemia ; on followup over a third of the women and over a quarter of the men were still iron-deficient. There is thus considerable evidence that once anaemia has been detected these subjects are more likely to be anaemic subsequently. The figures from the present survey suggest that this likelihood is increased in the selected subjects identified in general practice (Fry, 1961) and in hospital patients (Beveridge et al., 1965) compared with the unselected populations studied in this report.

We thank Professor A. L. Cochrane, director, and members of the staff of the Medical Research Council's Epidemiology Unit (South Wales) for help throughout this work. We are grateful to the men and women in our samples for their co-operation.

REFERENCES

Beveridge, B. R., Bannerman, R. M., Evanson, J. M., and Witts, L. J. (1965). Quarterly fournal of Medicine, 34, 145.

Campbell, $H_{\text {., }}$ et al. (1968). British Fournal of Preventive and Social Medicine, 22, 41.

Cotes, J. E., et al. (1969). Fournal of Physiology, 203, 79P.

Elwood, P. C. (1964). British fournal of Preventive and Social Medicine,

Elwood, P. C., Waters, W. E., Greene, W. J. W., and Wood, M. M. (1967). British Medical fournal, 4, 714.

Elwood, P. C., Waters, W. E., Greene, W. J. W., Sweetnam, P., and Wood. M.' M. (1969). fournal of Chronic Diseases, 21, 615 .,

Fry, J. (1961). British Medical fournal, 2, 1732.

Fry, J. (1961). British Medical fournal, 2, 1732.

Kilpatrick, G. S., and Hardisty, R. M. (1961). British Medical fournal, 1, 778.

Pucher, G. W., Griffith, F. R., Brownell, K. A., Klein, J. D., and Carmer, M. E. (1934). Fournal of Nutrition, 7, 169.

\title{
Steady-state Plasma Levels of Nortriptyline in Twins: Influence of Genetic Factors and Drug Therapy
}

\author{
BALZAR ALEXANDERSON,* L.M.; DAVID A. PRICE EVANS, † M.D., PH.D., M.SC., F.R.C.P. \\ FOLKE SJÖQVIST, $¥$ M.D.
}

British Medical fournal, 1969, 4, 764-768

Summary : Nineteen identical (monozygotic) and 20

fraternal (dizygotic) sets of twins between 45 and 51 years of age were given nortriptyline orally in doses of $0.2 \mathrm{mg} . / \mathrm{kg}$. body weight three times daily for eight days. The steady-state plasma concentrations of nortriptyline were calculated from the mean of the determinations for days 6,7 , and 8 . Identical twins, not treated with other drugs, achieved similar steady-state plasma concentrations of nortriptyline in contrast to fraternal twins who were not given other drugs. The intrapair similarity in steadystate plasma concentrations was not found in identical twins simultaneously treated with various drugs during the experiment. Identical and fraternal twins treated with drugs containing barbiturates had considerably lower steady-state plasma concentrations of nortriptyline compared with untreated twins.

It is concluded that most of the variability in nortriptyline steady-state plasma concentration between persons who have not received drugs is genetically determined. Exposure to other drugs also influences the steady-state plasma concentration of nortriptyline, which in a given patient may therefore be determined by a resultant of genetic and environmental factors.

* Research Assistant, Department of Pharmacology (Division of Clinical Pharmacology), Karolinska Institutet, S-104 01, Stockholm 60 , Sweden.

† Professor of Medicine, University of Liverpool, Liverpool, England.

¥ Lecturer in Clinical Pharmacology, Department of Pharmacology (Division of Clinical Pharmacology), Karolinska Institutet, S-104 01 Stockholm 60, Sweden.

\section{Introduction}

It has recently been established that patients who are treated with the same dose of various tricyclic antidepressants such as desipramine (desmethylimipramine) or nortriptyline show great differences in their steady-state plasma levels (Hammer and Sjöqvist, 1967 ; Sjöqvist et al., 1968). For desipramine (25 mg. t.i.d.) a range between 8 and $295 \mathrm{ng} . / \mathrm{ml}$. plasma has been observed (Hammer and Sjöqvist, 1967 ; Sjöqvist et al., 1968) and for nortriptyline, given in the same dose, steadystate plasma levels have been shown to vary fortyfold between patients (this laboratory, unpublished). Extensive pharmacokinetic investigations led to the suggestion that the steady-state plasma level of these drugs is mainly determined by their rate of metabolism, since only small individual differences were found in the plasma protein binding, degree of absorption, and renal elimination of these compounds in man (Hammer and Sjöqvist, 1967 ; Sjöqvist et al., 1968, 1969 ; Borgå et al., 1969).

The metabolism of drugs in man may be influenced by both genetic (Evans, 1968) and environmental factors, such as exposure to other drugs (Levi et al., 1968) and insecticides (Kolmodin et al., 1969). In heavily drug-treated psychiatric patients it is impossible to evaluate the relative contribution of either factor to the quoted interindividual differences in steady-state plasma levels of tricyclic antidepressants.

This work was undertaken with a dual purpose: (a) to study the role of genetic factors in determining the steady-state plasma levels of nortriptyline, and $(b)$ to assess the influence of concomitant drug therapy on this pharmacokinetic value. 


\section{Material and Methods}

Seventy-eight identical and fraternal twins, all between 45 and 51 years of age, and with one exception from the Stockholm area (monozygotic male, code 21, moved from Stockholm to Gotland in September 1968), voluntarily participated in this study (Table I a, b, and c). ${ }^{1}$ Initially 105 pairs of twins were invited by letter through the Swedish National Twin Register, Solna, but for various reasons 66 pairs dropped out (17 not interested, 30 currently registered addresses incorrect or no answer to inquiry, 11 unable to participate because of occupation, 5 a member in hospital, and 3 dead).

TABLE II.-Analyses of Variance of Monozygotic " Not-Drug-Exposed" Twin Pairs

\begin{tabular}{|c|c|c|c|c|}
\hline \multicolumn{2}{|l|}{$\begin{array}{c}\text { Source } \\
\text { of Variance }\end{array}$} & $\begin{array}{l}\text { Degrees of } \\
\text { Freedom }\end{array}$ & $\begin{array}{l}\text { Sum of } \\
\text { Squares }\end{array}$ & $\begin{array}{l}\text { Mean } \\
\text { Square }\end{array}$ \\
\hline $\begin{array}{l}\text { Between sexes } \quad . \\
\text { Within sexes } \quad . \\
\text { Between pairs within sexes } \\
\text { Within pairs within sexes } \\
\text { Between individuals within pair } \\
\text { Within individuals within pairs } \\
\text { Between days within individual } \\
\text { Within days within individuals }\end{array}$ & $\begin{array}{l}\because \\
\because \\
\because \\
\because \\
\because \\
\therefore\end{array}$ & $\begin{array}{r}1 \\
159 \\
7 \\
152 \\
9 \\
143 \\
36 \\
107\end{array}$ & $\begin{array}{r}6 \cdot 61 \\
7,979 \cdot 64 \\
6,392 \cdot 39 \\
1,587 \cdot 25 \\
227 \cdot 25 \\
1,360 \cdot 00 \\
922 \cdot 00 \\
\mathbf{4 3 8} \cdot 00\end{array}$ & $\begin{array}{r}6 \cdot 61 \\
50 \cdot 19 \\
913.20 \\
10 \cdot 44 \\
25 \cdot 25 \\
9.51 \\
25 \cdot 61 \\
4.09\end{array}$ \\
\hline Total & $\ldots$ & 160 & $7,986 \cdot 25$ & 49.91 \\
\hline
\end{tabular}
(A) $F(36: 107)=25.61 \div 4.09=6.26 ; P<0.000$

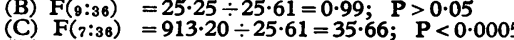

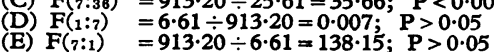

All subjects were Caucasian and with four exceptions healthy, as determined by history and physical examination, including electrocardiogram and routine laboratory analyses (haemoglobin, sedimentation rate, screening for protein and glucose in urine) The four exceptions were: (1) a man aged 50 (code No. 45) with cirrhosis of the liver diagnosed in 1967 ; laboratory studies (including haemogram, urine analysis, serum proteins, blood glucose, serum creatinine, bilirubin, aspartate aminotransferase, alanine aminotransferase, alkaline phosphatase, and thymol turbidity) showed normal results three weeks before the study; (2) a woman aged 51 (code No. 56) with grand-mal epilepsy; she was well controlled on diphenylhydantoin and phenobarbitone ; (3) a woman aged 48 (code No. 57) with unconfirmed but drug-treated (isoniazid and para-aminosalicylic acid) tuberculosis; (4) a woman aged 51 (code No. 82) with thyroid carcinoma in 1958 ; she was well controlled on thyroid substitution therapy. From the clinical point of view there were no objections to include these four subjects in the study.

Each volunteer was typed for 12 different blood- and serumgroup systems (ABO, MNS, P, K, Le, Fy, Jk, Rh, Gc, Hp, $\mathrm{Gm}, \mathrm{Ag}$ ) and red cell acid phosphatase, and the saliva was analysed regarding secretor or non-secretor to establish the nature of the twinship. Nineteen pairs were monozygotic and 20 dizygotic, in agreement with the records of the National Twin Register.

A careful drug history was obtained from all subjects. Twenty-one pairs did not use drugs for at least one year and were classified as "not exposed to drugs." In 18 pairs one or in some cases both twins were simultaneously treated with other drugs (Table I d). These were classified as "drug-exposed."

We also inquired about the living habits of the twins, with special emphasis on smoking and exposure to chemicals at home or at work.

Administration of Nortriptyline.-All subjects were given nortriptyline (5-(3-methylaminopropylidene)-10,11-dihydro- $5 \mathrm{H}$ dibenzo (a, d) cycloheptene chloride) $0.2 \mathrm{mg} . / \mathrm{kg}$. body weight by mouth three times daily for eight days. The drug was dispensed as gelatin capsules at the Military Pharmacy, Karolinska Hospital, Stockholm. Lactose was used as excipient. The capsules were taken at 6 a.m., 2 p.m., and 10 p.m.

Copies of Table I, giving code numbers and details of all 39 pairs of twins, can be obtained from Dr. B. Alezanderson, Division of Clinical Pharmacology, Department of Pharmacology, Karolinska Institutet, Fack, S-104 01 Stockholm 60, Sweden.
Plasma Samples and Analysis of Nortriptyline.-Blood specimens were drawn between 11 a.m. and 1 p.m. on days 6, 7 , and 8 of drug therapy and placed in heparinized tubes. The blood was centrifuged for 10 minutes at 2,000 r.p.m. Then $6 \mathrm{ml}$. of plasma was removed and mixed with $1.5 \mathrm{ml}$. of $0.1 \mathrm{~N}$ $\mathrm{HCl}$. The plasma samples were stored at $-20^{\circ} \mathrm{C}$. and later assayed for nortriptyline according to the method of Hammer and Brodie (1967) as described by Sjöqvist et al. (1969). All specimens were coded, the analyst being kept unaware of the relationship between the twins and about their classification as "drug exposed" or " not drug exposed." Each plasma sample was analysed in triplicate with five exceptions (Table I b and c). The steady-state level used for calculation was the mean of the concentrations on days 6,7 , and 8 .

Statistical Methods.-The statistical analysis of the variances is based on a nested classification according to Snedecor and Cochran (1967). The total variation was divided into component sums of squares corresponding to the variation between and within sexes, pairs, individuals, and days (Tables II, III, and IV).

\section{Results}

Methodological Error.-The variance within days within individuals represents the methodological error. There is a small difference of the variance within days within individuals between not-drug-exposed dizygotic and monozygotic twins; $F_{(143: 107)}=5.73 / 4.09=1.40 ; 0.05>P>0.025$ (Tables II and III) So far we cannot explain this. The methodological error should be equal in drug-exposed and not-drug-exposed twins provided that simultaneous treatment with other drugs does not interfere with the analysis of nortriptyline. In two subjects (code Nos. 63 and 65) treated with dextropropoxyphene chloride (Doloxene) during the experiment the plasma blanks diverged from those of the respective sib. This compound was found to interact with the analysis of nortriptyline. Both the involved twinships were excluded from the calculations.

TABLE III.-Analyses of Variance of Dizygotic "Not-Drug-Exposed" Twin Pairs

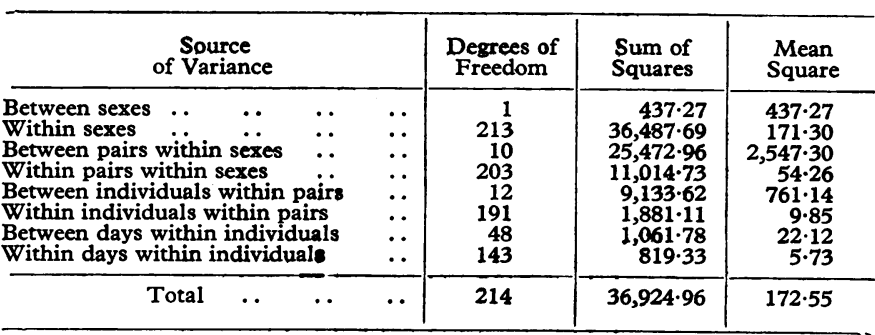

(F) $F(48: 143)=22 \cdot 12 \div 5.73=3.86 ; P<0.0005$

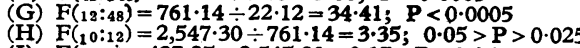

(I) $F(1: 10)=437 \cdot 27 \div 2,547 \cdot 30=0 \cdot 17 ; P>0.05$

TABle IV.-Analyses of Variance of Monozygotic "Drug-Exposed" Twin Pairs

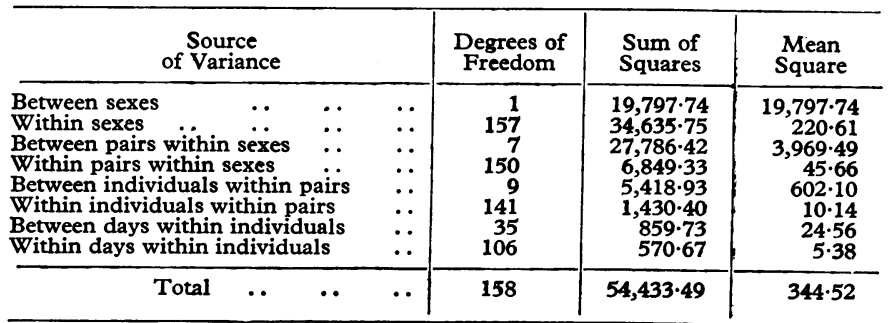

(L) $F(25: 108)=24.56 \div 5 \cdot 38=4.57 ; P<0.0005$

(N) $\mathrm{P}(7: 0)=3,969 \cdot 49 \div 602 \cdot 10=6.59 ; 0.01>\mathrm{P}>0.005$

(O) $\mathrm{F}(1: 7)=19,797 \cdot 74 \div 3,969-49=4 ; 99 ; \mathrm{P}>0.05$

The total degrees of freedom are not equal in Tables II and IV despite the numbers of twinships being equal in Figs 2 and 4 . This is because of a few missing determinations. In the complete experimemt five plasma samples could be processed in duplicate only (and not in triplicate); and 
Interindividual Differences in Steady-state Plasma Levels of Nortriptyline in Entire Material.-Fig. 1 shows the interindividual differences in steady-state plasma concentrations of nortriptyline in both drug-exposed and not-drug-exposed twins. The range between the extremes is tenfold $(8-78 \mathrm{ng} . / \mathrm{ml}$. plasma). twins who were on treatment with various drugs during the experiment (Fig. 4). The statistical calculations revealed significant differences in steady-state plasma concentrations of nortriptyline both between individuals within the pairs (F-ratio $(\mathrm{M}), \mathrm{P}<0.0005)$ and between the pairs (F-ratio $(\mathrm{N}), 0.01>$ $P>0.005$ ) (Table IV). Fig. 5 shows the steady-state plasma
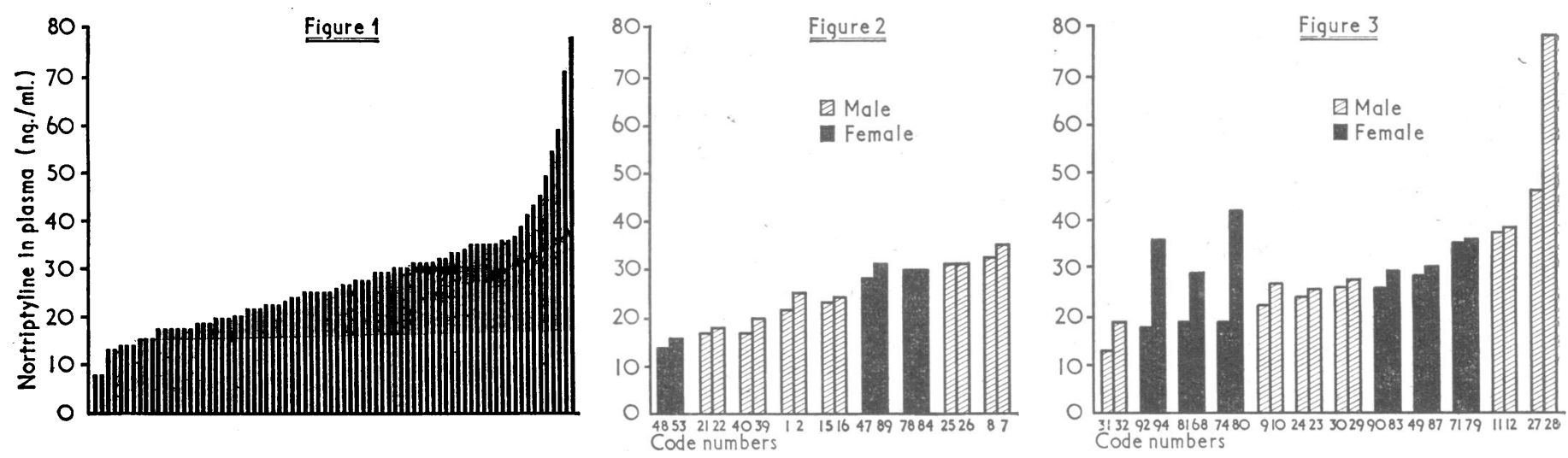

FIG. 1.-Histogram of entire material except for two subjects, code Nos. 63 and 65 (see Table Ic). Fig. 2.-Mean nortriptyline plasma concentration of days 6,7 , and 8 in identical twins previously not exposed to d rugs. FIG. 3.-Mean nortriptyline plasma concentration of days 6, 7, and 8 in fraternal twins previously not exposed to drugs.

Not-drug-exposed Twins.-Monozygotic twins, previously not treated with other drugs, achieved practically the same steady-state plasma concentration of nortriptyline. The individual steady-state levels varied from 14 to $35 \mathrm{ng} . / \mathrm{ml}$. plasma (Fig. 2). The analysis of variance did not indicate any differences in the steady-state plasma concentrations between individuals within the pairs (F-ratio (B), $P>0.05$ ). There were significant differences between the pairs (F-ratio (C) $\mathrm{P}<0.0005$ ) (Table II). Dizygotic twins not taking other drugs (Fig. 3) showed significant intrapair (F-ratio (G), P<0.0005) and interpair (F-ratio $(\mathrm{H}), 0.05>\mathrm{P}>0.025$ ) differences in steady-state plasma concentrations of nortriptyline (Table III).

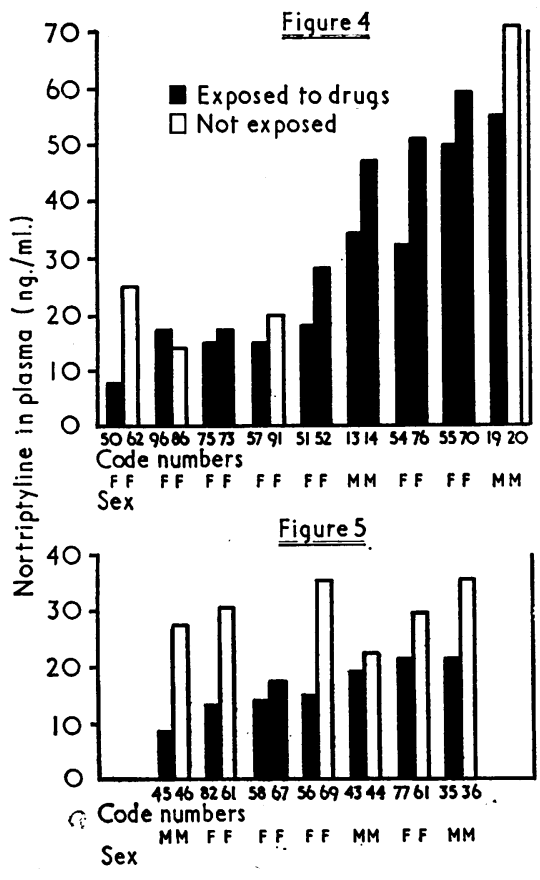

FIG. 4.-Mean nortriptyline plasma concentration of days 6,7 , and 8 in identical centration of days 6,7 , and 8 in identical twins exposed to different drugs. FIG. 5 . days 6,7 , and 8 in fraternal twins exposed to different drugs.

Drug-exposed Twins. - The intrapair similarity in steadystate plasma concentrations was not found in monozygotic concentrations of nortriptyline found in drug-exposed dizygotic sets of twins. Fraternal and identical twins treated with various drugs containing barbiturates had considerably lower steady-state plasma concentrations of nortriptyline than the untreated control twins (code Nos. $50+62,19+20$, Fig. 4 ; code Nos. $56+69,43+44,77+66$, Fig. 5). The monozygotic twins (code Nos. 73 and 75), both of whom were on drugs containing barbiturates, had similar but comparatively low (17 and $15 \mathrm{ng} . / \mathrm{ml}$. respectively) steady-state plasma levels of nortriptyline (Fig. 4).

There was no significant correlation in this study between smoking habits (cigarettes per day) and the steady-state plasma concentration of nortriptyline (Table $I$ a, b, and c); $r=-0.1526 ; F_{(1: 48)}=1.14 ; P>0.05$. There were no differences between sexes in steady-state plasma levels (F-ratios (D), (E), (I), (K), and (O), P>0.05).

The steady-state plasma concentrations of nortriptyline differed significantly between the days within the individuals (F-ratios (A), (F), and (L), P<0.0005). This may be expected because the steady-state plasma concentration fluctuates to a small extent in relation to the dosage interval. As mentioned above, the plasma samples were taken any time between 11 a.m. and 1 p.m.

\section{Discussion}

After repetitive oral administration of a constant dose of nortriptyline at fixed intervals the plasma concentration of the drug increases successively until a steady state is achieved. In agreement with earlier findings in patients on treatment with nortriptyline (Hammer and Sjöqvist, 1967 ; Sjöqvist et al., 1968) our results show that healthy adults develop different steady-state plasma concentrations when treated with the same dose of nortriptyline per kilogram body weight.

This twin study shows that most of the variability in nortriptyline steady-state plasma concentration between notdrug-treated individuals is genetically determined. All identical twins lived apart in different households; therefore the close resemblance in steady-state plasma concentrations of nortriptyline cannot be accounted for by exposure to common environmental factors.

It is known that individual variations in absorption, plasma protein, and tissue binding, rate of metabolism, and renal elimination may affect the steady-state plasma concentration of 
a drug. Therefore it is important to unravel the possible pharmacological factors involved. Monomethylated tricyclic antidepressants are easily absorbed from the intestine (Bernhard and Beer, 1962 ; Hermann, 1963 ; Yates et al., 1963 ; Sjöqvist and Borgå, 1969, unpublished). The renal excretion of unchanged nortriptyline has been shown to account for less than $5 \%$ of the daily dose at a steady-state plasma concentration in man (Sjöqvist et al., 1968, 1969). The interindividual differences in binding of desipramine and nortriptyline to plasma proteins are negligible (Borgå et al., 1969) compared with the observed variations in steady-state plasma concentrations. This may not necessarily exclude some interindividual differences in tissue binding.

Under steady-state conditions the amount of absorbed drug should be equal to the amount eliminated. The plasma concentration is kept almost constant in equilibrium with the body tissues. For these reasons the steady-state plasma concentration seems to be generally a much more accurate pharmacokinetic value than, for example, the plasma half-life following a single oral dose. The latter value is more dependent on fluctuations in rates of absorption and distribution. If, however, the drug is discontinued after steady-state has been established the plasma half-life will then more accurately reflect the rate of elimination, since the tissues are equilibrated with the drug (Hammer et al., 1967). Vesell and Page (1968a, 1968b, 1968c) reported that the pronounced differences between individuals in antipyrine, phenylbutazone and dicoumarol metabolism are primarily under genetic rather than environmental control, taking the plasma half-life of a single oral dose as an index of drug metabolism.

According to van Rossum and Tomey (1968) and van Rossum (1968) the steady-state plasma concentration (C) of a drug is directly proportional to the maintenance dose (Q) and half-time for elimination $\left(t \frac{1}{2}\right)$ and is inversely proportional to the dosage interval $(\Delta t)$ and the "volume of distribution" $(V)$ as to be expressed mathematically:

$$
\mathrm{C}=1 \cdot 44 \frac{\mathrm{Q} \cdot \mathrm{t} \frac{1}{2}}{\mathrm{~V} \cdot \Delta \mathrm{t}}
$$

van Rossum and Tomey (1968) also reported that this formula is satisfied by the data on steady-state kinetics of desipramine in man obtained in this laboratory (Hammer and Sjöqvist, 1967).

The volume of distribution (V) is the ratio of the concentration of drug in the body (mg./ $/ \mathrm{kg}$.) to the concentration in plasma (mg./1.) and hence an index of accumulation in body tissues. $\mathrm{V}$ is readily computed from the decline in plasma concentrations after parenteral administration of a known amount of drug (Brodie and Reid, 1967). If the maintenance dose and the dosage interval are kept constant interindividual variations in steady-state plasma concentrations will be due to differences in $t \frac{1}{2}$ and/or $V$, provided that absorption of the drug is complete. It will be of interest to try in the future to evaluate the relative importance of both volume of distribution and rate of metabolism in regulating the steady-state plasma concentration of nortriptyline.

None of the kinetic values for nortriptyline discussed so far except $t \frac{1}{2}$ seems to involve active enzymatic processes. The pronounced interindividual differences in steady-state plasma levels of nortriptyline could be explained by corresponding differences in the metabolism of the compound. It may be possible to identify genetic polymorphisms in the activity of enzymes controlling individual chemical biotransformations. Recent cross-over studies show that psychiatric patients treated with the structurally related compounds nortriptyline and desipramine achieve similar plasma concentrations on both drugs (Hammer et at., 1967).

Nortriptyline is metabolized by hydroxylation, desmethylation, and conjugation with glucuronic acid in the rat (McMahon et al., 1963) and in man, where hydroxylation seems to be the major metabolic pathway (Hammer, and Sjöqvist, unpublished data).
From extensive animal investigations it is well known that phenobarbitone and other barbiturates may accelerate the metabolism of drugs by increasing the activity of hydroxylating enzymes in liver microsomes (cf. Burns and Conney, 1965).

In two identical and three fraternal sets of twins one of the sibs respectively was on concomitant treatment with various drugs containing barbiturates. All these individuals had considerably lower steady-state plasma levels of nortriptyline than the untreated control twins. In one monozygotic pair (code Nos. 73 and 75) both individuals were on barbiturate treatment. These twins not only achieved low steady-state levels of nortriptyline (17 and $15 \mathrm{ng} . / \mathrm{ml}$. plasma) compared with the total range in steady-state concentrations $(8-78 \mathrm{ng} . / \mathrm{ml}$. plasma) but they also showed a remarkable intrapair similarity.

So far it is not clarified whether barbiturates or other drugs may interfere with the absorption of tricyclic antidepressants or change their volume of distribution. Regarding the latter, it is possibly relevant that phenobarbitone does not affect the binding of desipramine to plasma proteins (Borgå et al., 1969). These facts suggest that the steady-state level of nortriptyline is decreased in barbiturate-treated twins owing to induction of microsomal drug-metabolizing enzymes.

Only two individuals asserted exposure to chemical agents at home or at work. These two (code Nos. 13 and 14)monozygotic "drug-exposed" males-are in close contact with gases and different chemicals in their daily work as welders.

Our data show that, besides genetic factors, concomitant drug exposure is fundamentally important in determining the steadystate plasma levels of nortriptyline. Thus the intrapair similarity in steady-state level of nortriptyline was not found in monozygotic twins who were treated with other drugs during the experiment.

This finding has clinical implications in relation to the extensive drug combinations commonly used in the treatment of psychiatric disorders. Fixed combinations of antidepressants and potential inducers of drug metabolism are often used. Probably drug interactions have not been recognized in clinical psychopharmacology owing to the difficulties in assessing both therapeutic and adverse effects quantitatively. Accumulating evidence indicates that the pharmacological effects of nortriptyline are directly related to its steady-state plasma concentration (Freyschuss et al., 1969, and unpublished data). It therefore becomes important to recognize factors determining this pharmacokinetic value. In this regard nortriptyline may be looked on as a model for a great number of currently used drugs.

We thank Miss Margareta Lind and Mrs. Ingegerd Bertling for skilful technical assistance. We also thank Dr. Karl Ytterborn and Dr. Nils Ryman, department of genetics, University of Stockholm, for genetical and statistical consultations ; Dr. Rune Cederlö, the Swedish National Twin Register (Stockholm), and Dr. Torbjörn Lundman (Stockholm) for helpful advice; Professor Birger Broman and Dr. Jan Mörner, State Institute for Blood Group Serology, for the numerous serological determinations. One of us (D. A.P.E.) acknowledges a travel stipend from British Geigy.

This study was supported by the Swedish Medical Research Council (B69-21x-1021-04 and K69-21x-2749-G01), by the National Institutes of Health, Bethesda, Maryland, U.S.A. (GM 13978-03), and by funds from Karolinska Institutet.

Requests for reprints should be addressed to: Dr. B. Alexanderson, Division of Clinical Pharmacology, Department of Pharmacology, Karolinska Institutet, Fack, S-104 01 Stockholm 60, Sweden.

\section{REFERENCES}

Bernhard, K., and Beer, H. (1962). Helvetica Physiologica et Pharmacologica Acta, 20, 114

Borgå, O., Azarnoff, D. L., Plym Forshell, G., and Sjöqvist, F. (1969). Biochemical Pharmacology, 18, 2135.

Brodie, B. B., and Reid, W. D. (1967). Federation Proceedings, 26, 1062 . 
Burns, J. J., and Conney, A. H. (1965). Proceedings of the Royal Society
of Medicine, 58, 955. Evans, D. A. P. (1968). Annals of the New York Academy of Science, $151,723$.

Freyschuss, U., Sjöqvist, F., Tuck, D., and Assberg, M. (1969). Pharmacologica Clinica. In press.

Hammer, W. M., and Brodie, B. B. (1967). Fournal of Pharmacology and Experimental Therapeutics, 157, 503.

Hammer, W., Ideström, C.-M., and Sjöqvist, F. (1967). In Antidepressant Drugs, edited by S. Garattini and M. N. G. Dukes, p. 301. Amsterdam, Excerpta Medica

Hammer, W., and Sjöqvist, F. (1967). Life Sciences, 6, 1895.

Herrmann, B. (1963). Helvetica Physiologica et Pharmacologica Acta, 21,402 .

Kolmodin, B., Azarnoff, D. L., and Sjöqvist, F. (1969). Clinical Pharmacology and Therapeutics, $10,638$.

Levi, A. J., Sherlock, S., and Walker, D. (1968). Lancet, 1, 1275.

McMahon, R. E., Marshall, F. J., Culp, H. W., and Miller, W. M.

(1963). Biochemical Pharmacology, 12, 1207.
Sjöqvist, F., Hammer, W., Borgå, O., and Azarnoff, D. L. (1969). In Collegium Internationale Neuro-psychopharmacologicum: The Present Status of Psychotropic Drugs, edited by A. Cerletti and F. J. Bové, p. 128. Amsterdam, Excerpta Medica.

Sjöqvist, F., et al. (1968). In Toxicity and Side-effects of Psychotropic Drugs, edited by S. B. de C. Baker, J. R. Boissier, and W. Koll, p. 246. Amsterdam, Excerpta Medica.

Snedecor, G. W., and Cochran, W. G. (1967). Statistical Methods, 6th ed., p. 285. Ames, The Iowa State University Press.

van Rossum, J. M. (1968). Fournal of Pharmaceutical Sciences, 57, 2162. van Rossum, J. M., and Tomey, A. H. M. (1968). Fournal of Pharmacy and Pharmacology, 20, 390

Vesell, E. S., and Page, J. G. (1968a). Science, 159, 1479.

Vesell, E. S., and Page, J. G. (1968b). fournal of Clinical Investigation, $47,2657$.

Vesell, E. S., and Page, J. G. (1968c). Science, 161, 72.

Yates, C. M., Todrick, A., and Tait, A. C. (1963). Fournal of Pharmacy and Pharmacology, 15, 432.

\title{
Human Babesiosis in Ireland: Further Observations and the Medical Significance of this Infection
}

\author{
ital

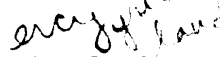 \\ P. C. C. GARNHAM,* C.M.G., M.D., D.sC., F.R.S.; JOSEPH DONNELLY, † B.SC. \\ HARRY HOOGSTRAAL, $\ddagger$ M.S., PH.D., F.R.E.S. ; C. COTTON KENNEDY,§ D.M., F.C.PATH. \\ GERALD A. WALTON, $\|$ M.B., M.SC., F.R.E.S.
}

[With Colour Plate]

British Medical fournal, 1969, 4, 768-770

\begin{abstract}
Summary : Three splenectomized persons in Yugoslavia, $\checkmark$ California, and Ireland have been reported to be infected by three different Babesia species; two cases were fatal. In a study of the site where the fatal infection was contracted in Ireland, blood samples from 36 persons who had recently been bitten by ticks were inoculated into two splenectomized calves; no response to Babesia divergens was detected. Field-collected Ixodes ricinus ticks inoculated into another splenectomized calf resulted in fever and recovery of the agent of tick-borne fever (Cytoecetes phagocytophilia). This attempt to determine the presence of latent infection in human beings with intact spleens should be repeated on a larger scale in areas with a demonstrably high incidence of Babesia in ticks and animals. Few places in the world are free of piroplasms; their presence may present a hazard to splenectomized persons or to those whose splenic function is deficient.
\end{abstract}

\section{Introduction}

Three human cases of babesiosis have now been reported in the literature. Each occurred in a person who had undergone splenectomy some time previously, and was severe or fatal. Human beings with an intact spleen are apparently insusceptible to this cosmopolitan protozoal infection of the lower vertebrates.

The first human case was reported from Yugoslavia (Skrabalo and Deanovic, 1957). A farmer living on the outskirts of Zagreb had suffered internal injuries in a car accident 11 years

* Professor Emeritus, Imperial College of Science, Ascot, Berks.

† Senior Research Officer II, Central Veterinary Laboratory, New Haw, Weybridge, Surrey.

₹ From Research Project MF12.524.008-3010, Bureau of Medicine and Surgery, Department of the Navy, Washington, D.C. The opinions and assertions contained herein are the private ones of the author
and are not to be construed as official or as reflecting the views of the Department of the Navy or of the naval service at large. earlier and his spleen had been removed. He remained well until June 1956, when he was admitted to hospital very ill with fever, anaemia, jaundice, and haemoglobinuria. His blood contained numerous intraerythrocytic "rings" (Colour Plate, Fig. 1) which were identified as Plasmodium falciparum (Colour Plate, Fig. 2), and the condition was thought to be blackwater fever. The patient died eight days later. The rather unusual characters of the case raised some suspicion about the correctness of the diagnosis, and the blood films were sent for confirmation to Drs. N. H. Swellengrebel, R. Geigy, and E. Mudritz, and to one of us (P.C.C. G.). Each replied that the infection was babesial, not malarial. It seemed possible that the slides had been muddled with veterinary ones, but corpuscle measurements quickly confirmed that the cells were of human and not bovine dimensions. Epidemiological inquiries showed that the farm where the man lived was infested by ticks (Dermacentor silvarum and Ixodes ricinus) and that the cattle he had tended were infected with Babesia bovis.

The second case occurred in California in 1966 in a man who had visited relatively isolated coastal areas near San Francisco during the months preceding illness. $\mathrm{He}$ was admitted to hospital with chills and fever, diagnosed as a case of malaria, placed on $250 \mathrm{mg}$. of chloroquine weekly for about 15 weeks, and recovered (Scholtens et al., 1968). Because of hereditary spherocytosis, a splenectomy had been performed on the patient in 1964, at which time he received 13 units of blood. The case was diagnosed as babesiosis (Babesia sp.) when "Maltese-cross"-type organisms, but no malarial parasites, were found on the blood slides. Animal inoculations with blood taken about 90 days after onset of illness demonstrated no organisms. Babesia antibodies in the patient's serum were found in both complement-fixation and tube latex-agglutination tests.

$\checkmark$ Consultant Clinical Pathologist, Belfast City Hospital, Belfast, Northern Ireland.

Department of Zoology, University College, Cork, Ireland.

Sut see Fitzpatrick et al. (1969) regarding a newly described fourth instance of human babesiosis. 